\title{
Wayang Hip Hop \\ Dekonstruksi Budaya Tradisi di Yogyakarta
}

\author{
Aji Santoso Nugroho \\ Jurusan Musik Nusantara Program Pasca Sarjana Institut Seni Indonesia Yogyakarta \\ Email: ajisantosonugroho@yahoo.co.id
}

\begin{abstract}
This paper aims to observe the presence of the Hip Hop Puppet in the middle of the Yogyakarta community which is developing quite dynamically. Talcott Parsons's theory of social action and Derridas deconstruction theory is used as a theoretical framework to explain the presence of this Hip Hop Puppet. The theory was chosen because the Hip Hop Puppet was created by Ki Catur Kuncoro by fusing two cultures and simultaneously deconstructing the pure shadow puppets that were present first. Hip Hop puppets were created to meet the needs of today's young generation. The Hip Hop Puppet was created by Ki Catur Kuncoro with the aim that the young generation does not lose their cultural roots and at the same time still be able to keep up with the times. In addition, the Hip Hop Puppet is intended as an alternative media to convey criticism and proof that traditional culture can be aligned with modern culture. The acceptance of the Hip Hop Puppet as a spectacle that attracts audiences from all walks of life, proves that there is a cultural change in the middle of the social life of the people of Yogyakarta.
\end{abstract}

Keywords: deconstruction; puppet; Hip Hop music

\begin{abstract}
Abstrak
Tulisan ini bertujuan mengamati kehadiran Wayang Hip Hop di tengah masyarakat Yogyakarta yang berkembang cukup dinamis. Teori Talcott Parsons tentang tindakan sosial dan teori dekonstruksi Derrida digunakan sebagai kerangka teori untuk menjelaskan kehadiran Wayang Hip Hop ini. Dipilihnya teori tersebut karena Wayang Hip Hop diciptakan oleh Ki Catur Kuncoro dengan meleburkan dua kebudayaan dan sekaligus mendekonstruksi wayang kulit purwa yang telah hadir lebih dulu. Wayang Hip Hop diciptakan untuk memenuhi kebutuhan generasi muda zaman sekarang. Wayang Hip Hop diciptakan Ki Catur Kuncoro dengan tujuan agar generasi muda tidak kehilangan akar kebudayaan dan sekaligus tetap dapat mengikuti arus perkembangan zaman. Selain itu Wayang Hip Hop dimaksudkan sebagai media alternatif untuk menyampaikan kritik dan sebuah pembuktian bahwa budaya tradisi dapat disejajarkan dengan budaya modern. Diterimanya Wayang Hip Hop sebagai tontonan yang menarik penonton dari semua kalangan, membuktikan bahwa terjadi perubahan budaya di tengah kehidupan sosial masyarakat Yogyakarta.
\end{abstract}

Kata kunci: dekonstruksi; wayang; musik Hip Hop 


\section{Pendahuluan}

Perubahan zaman yang dipacu oleh gelombang globalisasi menjadi tantangan berat bagi eksistensi kesenian tradisional. Kesenian yang modern, terbaru, atau mutakhir dalam kebudayaan lazim dipertentangkan dengan yang tradisional. Asumsi itu pada akhirnya mendudukkan sesuatu yang tradisional selalu dianggap "kuno" dan ketinggalan zaman, sedangkan yang modern selalu berhubungan dengan "trend", terbarukan, dan sesuai dengan zamannya. Dalam dunia kesenian, orang beranggapan bahwa kesenian modern akan mengalahkan kesenian tradisional. Kesenian modern dianggap lebih mampu diterima dan dinikmati khususnya oleh generasi muda. Oleh karena itu, perubahan zaman yang menuntut modernisasi menjadi tantangan berat bagi eksisistensi kesenian tradisional.

Perubahan sosial yang berkaitan dengan perubahan budaya, sangat bersinggungan dengan perkembangan kesenian di Yogyakarta. Tidak dapat dipungkiri bahwa kehidupan seni dan kesenian masih sangat subur di tengah kehidupan masyarakat. Seni dan kesenian tersebut juga terus berkembang diperlihatkan dengan perubahan-perubahan dalam setiap pertunjukkannya. Perubahan tersebut baik dalam segi penambahan unsur lain maupun pemunculan unsur yang benar-benar baru dalam konteks tuntutan selera seni masyarakat. Salah satu fenomena tersebut adalah munculnya Wayang Hip Hop di Yogyakarta. Wayang Hip Hop merupakan hasil kolaborasi seniman Catur Kuncoro dengan Grup Hip Hop km 7 Jogja. Konsepnya sangat berbeda dengan wayang purwa yang masih setia pada pakem tradisi. Dalam Wayang Hip Hop, Ki Catur Kuncoro mengkombinasikan tokoh wayang purwa dengan konsep yang lebih mengarah ke masa kini. Tentu lakon yang dibawakan Ki Catur Kuncoro dalam Wayang Hip Hop juga tidak sesuai pakem yang sudah ada. Lima alasan untuk mengidentifikasi fenomena Wayang Hip Hop yaitu: (1) persimpangan musik yang kompleks, (2) adaptasi radikal cerita wayang klasik untuk mengatasi masalah-masalah kontemporer, (3) perluasan konvensi selingan komik pada adegan gara-gara menjadi fokus pertunjukan, (4) adaptasi kebijaksanaan Jawa untuk pengaturan baru, dan (5) adaptasi dari produksi, yang telah disajikan dalam konteks yang sangat beragam (Varela, 2014).
Memahami perubahan kebudayaan dalam sebuah masyarakat, dapat dilakukan dengan mengkaji keterkaitan hubungan saling mempengaruhi di antara faktor-faktor dari dua kebudayaan. Artinya masuknya pengaruh kebudayaan asing terhadap suatu kelompok masyarakat merupakan proses perubahan yang saling mempengaruhi antara seni itu sendiri.

\section{Tindakan Sosial Talcott Parsons dan Dekonstruksi Derrida}

Tulisan ini bertujuan mengetahui perkembang an salah satu bentuk seni pertunjukan di Yogyakarta yaitu Wayang Hip Hop di tengah masyarakat yang dinamis. Perkembangan ini akan dilihat dari sudut pandang perubahan kebudayaan. Teori Talcott Parsons tentang tindakan sosial dan teori dekonstruksi Derrida digunakan sebagai pisau analisis untuk menjelaskan proses berlangsungnya peleburan kebudayaan. Pandangan Parsons tentang tindakan yang diuraikan oleh Hendar Putranto (2005: 55) dalam Budaya dan Integrasi Sosial, Menelusuri Jejak Karya Talcott Parsons, menyebutkan bahwa sebuah model ideal tindakan manusia harus mempunyai unsur: (1) Tujuan (ends)= tujuan tindakan; (2) Sarana (means) = hal-hal yang memampukan si pelaku bertindak; (3) Syarat (conditions)= situasi-situasi dan batasan-batasan yang melingkupi tindakan; (4) Norma (norms)= pemahaman atas tujuan dan sarana mana yang sesuai dan bisa diterima; (5) Upaya (effort)= kerja atau upaya yang dikerahkan pelaku untuk menyelesaikan tindakan.

Dekonstruksi adalah suatu peristiwa yang tidak menunggu pertimbangan, kesadaran, atau organisasi dari suatu subjek, atau bahkan modernitas. Kata dekonstruksi bukan secara langsung terkait dengan kata destruksi melainkan terkait kata analisis yang secara etimologis berarti untuk menunda sinonim dengan kata mendekonstruksi. Terdapat tiga poin penting dalam dekonstruksi Derrida (Sutrisno, 2005), yaitu: (1) Dekonstruksi seperti halnya perubahan terjadi terus-menerus, dan ini terjadi dengan cara yang berbeda untuk mempertahankan kehidupan; (2) Dekonstruksi terjadi dari dalam sistem-sistem yang hidup, termasuk bahasa dan teks; (3) Dekonstruksi bukan suatu kata, alat, atau teknik yang digunakan dalam suatu kerja setelah fakta dan tanpa suatu subyek interpretasi. 
Pemikiran dekonstruktif Derrida berupaya untuk menunjukkan bahwa ada pemikiran lain yang bisa menjadi pemikiran alternatif disamping pemikiran yang telah ada. Konsep yang ia tawarkan ini bisa menjadi suara lebih bagi pemikiranpemikiran yang selama ini terpinggirkan oleh pemikiran tunggal yang menjunjung tinggi logosentrisme. Dekonstruksi tidak berarti menjurus pada penghancuran suatu konsep tanpa solusi. Namun dekonstruksi juga bisa menawarkan konsep baru untuk menggantikan konsep lama. Jika karakter tersebut dihidupkan kembali dalam bahasa, ia berharap bahwa filsafat tidak akan bisa lagi diklaim sebagai suatu otoritas kebenaran.

Pada langkah yang pertama, melibatkan penghancuran/pembongkaran gambar/tampilan yang sebelumnya mendominasi, mendukung apa yang tersembunyi, dan yang didominasi. Pada langkah yang kedua, melibatkan penghancuran/ pembongkaran kedua kutub, tetapi pada saat yang sama juga berlangsung perpindahan pada mereka, dan kesemuanya itu kemudian membangun suatu yang baru dan lebih luas.

\section{Bentuk Pertunjukan Wayang Kulit Pada Umumnya}

Pertunjukan atau penyajian wayang sangat erat hubungannya dengan unsur-unsur di dalamnya. Secara garis besar, unsur-unsur dalam pertunjukan wayang kulit pada umumnya adalah dalang, boneka wayang/properti, lakon/cerita, catur dan gamelan/ iringan yang digunakan.

\section{a. Dalang}

Subyek utama dalam pertunjukan wayang adalah dalang. Tugas dalang dalam hal ini sangat dominan. Dalang bertugas sebagai orang yang memainkan wayang, baik gerakan wayang maupun ucapan wayang. Dengan kata lain dalang sebagai nyawa dari setiap wayang. Perbedaan jenis karakter wayang harus dikuasai oleh seorang dalang. Selain itu dalang harus mampu menciptakan suasana adegan atau dramatik setiap tokoh, walaupun dalam penyajiannya didukung oleh karawitan. Penguasaan tentang gendinggending pakeliran juga harus dimiliki oleh seorang dalang. Penentuan gending dilakukan oleh dalang, karena dalang yang menentukan suasana suatu adegan. Dapat dikatakan bahwa dalang merupakan aktor penentu dalam sajian wayang, utamanya dalam mengatur dan menentukan gending yang akan dibunyikan (Supriyono, 2007: 21).

Tugas dalang di luar teknis penyajian adalah sebagai komunikator sosial. Seperti orang pada umumnya, dalang merupakan salah satu tokoh rakyat, yang hidup di lingkungan masyarakat. Oleh karena itu dalang lebih peka terhadap kebutuhan, keinginan, dan aspirasi / segala sesuatu yang dipikirkan rakyat. Sebagai komunikator sosial yang ia lakukan pada pentas dan pergelaran wayang, dalang dapat melakukan komunikasi sosial baik secara horisontal maupun vertikal (Haryanto, 1988:17). Sebagai contoh apabila seorang dalang melakukan kritik sosial melalui lawakan tokoh punakawan ia melakukan komunikasi vertikal. Sedangkan jika dalang menjabarkan tentang harapan dari rakyat, oleh rakyat, dan untuk rakyat, berarti dalang melakukan komunikasi horizontal. Dengan demikian tugas dalang sebagai komunikator sosial adalah penyambung harapan dari rakyat maupun pemerintah secara vertikal maupun horizontal.

\section{b. Wayang}

Boneka wayang merupakan obyek yang menjadi unsur utama dalam pertunjukan wayang. Pada umumnya boneka wayang terbuat dari kulit yang dipahat dan dicat sedemikian rupa sehingga menyerupai manusia dan setiap tokoh mempunyai perwatakan masing-masing. Perwatakan tersebut merupakan gambaran sifatsifat manusia dalam kehidupan sehari-hari. Namun selain terbuat dari kulit, terdapat juga wayang yang terbuat dari kayu yaitu wayang golek. Wayang ini berbentuk tiga dimensi dan hampir menyerupai manusia lengkap dengan kepala, badan, lengan, sogol (sumbu dan pegangan wayang), dan busana. Karakter masing-masing tokoh dapat dilihat pada raut muka wayang golek tersebut. Pembuatan raut muka dipertegas dengan rias / corekan atau istilah dalam wayang kulit ngulat-ulati. Rias tersebut berupa corekan kumis, corekan cambang, dan corekan alis (Sukistono, 1988: 15). Kemudian perabot busana wayang golek meminjam pembendaharaan dari busana wayang purwa, wayang gedog, wayang orang, dan kethoprak. 


\section{c. Lakon}

Lakon merupakan aspek terpenting dalam pertunjukan wayang. Nilai-nilai kemanusiaan dalam pertunjukan wayang akan terungkap melalui alur cerita yang terkandung dalam lakon. Pengertian lakon berasal dari kosakata bahasa Jawa yaitu laku mendapat akhiran an, yang mempunyai arti perjalanan. Dengan demikian pengertian lakon dalam pertunjukan wayang adalah perjalanan cerita wayang atau rentetan peristiwa wayang. Selain itu lakon juga dapat menunjuk pada tokoh atau judul cerita. Seperti pernyataan masyarakat yang menyebutkan "lakone sapa?", "lakone apa?". Misalnya lakon yang menceritakan gugurnya Adipati Karna dalam perang besar Baratayuda, lakon ini berjudul Karna Tanding dan tokoh utama adalah Adipati Karna. Dengan demikian, perjalanan cerita tersebut berhubungan erat dengan tokoh sebagai pelaku dan pengadegan yang mengandung permasalahan/konflik sebagai balungan lakon. Setiap jenis wayang menggunakan lakon yang mengacu atau bersumber dari beberapa kitab atau serat, misalnya Serat Mahabarata dan Ramayana.

d. Catur

Catur merupakan salah satu unsur garap dalam pertunjukan wayang. Catur adalah semua wujud bahasa atau wacana yang diucapkan oleh dalang dalam sajian pertunjukan wayang (Murtiyoso, 2004: 57). Pada tradisi pakeliran Yogyakarta, istilah catur disebut carita yang meliputi, janturan, kandha, dan antawecana. Dalam sajian wayang, catur meliputi beberapa aspek yaitu, janturan, kandha, dan antawecana. Janturan adalah wacana dalang yang berupa deskripsi suasana suatu adegan yang sedang berlangsung dengan ilustrasi gending garap sirep. Bahasa yang digunakan dalam janturan adalah bahasa campuran antara bahasa Jawa dengan bahasa Kawi. Kandha adalah ucapan dalang yang berupa narasi, pada umumnya menceritakan peristiwa yang telah, sedang dan akan berlangsung tanpa gending. Penggunaan bahasa sastra dalam kandha Wayang Golek Menak tidak jauh berbeda dengan Wayang Kulit Purwa. Antawecana yaitu dialog atau percakapan wayang yang dilakukan oleh dalang. Secara tradisi antawecana dalam suatu adegan/ jejer selalu diawali idiom-idiom konvensional, seperi: Hong Ilaheng, Jagad Dewa bathara, dan sebagainya.

\section{e. Gamelan/Musik}

Pada dasarnya gamelan atau karawitan tradisional di lingkungan masyarakat (Jawa) disajikan tidak terlepas dari fungsi dan kegunaannya untuk berbagai keperluan atau peristiwa (Supanggah, 2009: 129). Dalam penyajian pertunjukan wayang, kedudukan karawitan berkaitan dengan pembabakan maupun pengadegan, dan berperan penting dalam memperkuat atau mempertegas unsur dramatik. Rahayu Supanggah (2009) menyebutnya dengan istilah karawitan pakeliran. Sementara itu untuk menyebutkan komposisi musikal, para pengrawit menyebut karawitan tersebut sebagai gending wayangan. Gending wayangan, yaitu gending-gending yang biasa digunakan untuk mendukung pertunjukan Wayang Kulit Purwa, kemudian juga untuk Wayang Golek, Madya, dan Gedhog (Murtiyoso, 2004: 114). Pada masa sekarang ini dalam pertunjukan wayang tidak lagi batasan penggunaan gending. Semua gending, bahkan musik apapun (di luar gamelan) masuk sebagai iringan, seperti shalawatan (rebana), dangdut, campursari, dan sebagainya. Dampak dari peristiwa tersebut, musik atau karawitan lebih dominan dari pada pakeliran (pertunjukan boneka wayang). Dalam hal ini dalang sering berperan seperti pembawa acara atau MC.

\section{Deskripsi Penyajian Pertunjukan Wayang Hip Hop}

Wayang Hip-Hop dalam penyajiannya mencipta dan menggunakan lagu-lagu hip-hop dimainkan oleh seorang DJ yang kemudian dipadukan dengan pola-pola pada pewayangan, seperti pocapan, sulukan, janturan dan lainlain. Dalang Ki Catur Kuncoro duduk bersila, dengan dandanan tidak seperti dalang biasanya. Pakaian adat Jawa seperti blangkon, surjan, kain dikombinsikan dengan kacamata hitam dan sepatu kets. Berbeda dengan visual pertunjukan wayang kulit pada umumnya, dalam pertunjukan Wayang Hip Hop tidak terlihat bentangan kain putih yang disebut kelir sebagai media memainkan wayang. 
Hanya sepotong gedebog (batang pohon pisang) yang digunakan untuk menempatkan wayang. Selain itu tidak nampak lagi boneka wayang yang ditata berjejer di kanan kiri kelir. Selain itu terdapat modifikasi tokoh wayang purwa dengan konsep yang lebih kekinian. Pakaian tokoh-tokoh wayang tidak lagi berbahan kain layaknya dalam wayang purwa. Tokoh punakawan Gareng, Petruk dan Bagong misalnya, hadir dalam pakeliran bercelana jeans, berkaos katung, dan berkalung besar layaknya penyanyi rap. Sesuai pakainnya tokoh wayang punakawan tersebut berganti nama yaitu Gareng menjadi Garry, Petruk menjadi Petrik dan Bagong menjadi Bogy. Ki Catur juga memunculkan tokoh selebritis masa kini, seperti Lady Gaga, dibaurkan dengan tokoh Petruk dan yang lainnya. Selain itu, dalam sajiannya Ki Catur juga memasukkan boneka wayang golek.

Ki Catur memulai adegan pertama dengan suluk pewayangan. Namun demikian tidak lagi menggunakan gamelan sebagai iringannya, melainkan suara musik elektro hip hop dari disc jokey (DJ). Kemudian penyanyi hip hop melantunkan lagu hip hop dengan beat-beat cepat ala rapper dalam bahasa Jawa. Kemudian tokoh punakawan Petruk dan Gareng hadir dalam pakeliran sambil menari-nari mengikuti irama hip hop dari para penyanyi.

Konsep Wayang Hip Hop sangat berbeda dengan wayang purwa yang masih setia pada pakem tradisi. Pertunjukan wayang yang disajikan adalah salah satu adegan gara-gara, yang biasanya dalam pementasan wayang kulit selalu menampilkan sosok tokoh rakyat Semar beserta keluarganya, Petruk, Gareng, dan Bagong, yang sengaja dikemas menjadi suatu cerita yang menghibur (komedi). Cerita-cerita yang diangkat biasanya bertemakan kehidupan sosial masyarakat sehari-hari. Bahasa yang disajikan menggunakan bahasa campuran antara bahasa Indonesia dan Jawa. Selain itu dialog yang disampaikan juga menggunakan beberapa bahasa Internasional, sehingga mampu melakukan komunikasi dengan penonton dan membawa suasana yang tidak membosankan. Lakon yang dibawakan juga tidak sesuai dengan pakem dan banyak dilakukan perubahan. Cerita yang dimainkan pun banyak mengangkat kondisi sosial masa kini. Pilihan Ki Catur memang tidak semata-mata merupakan tuntutan tren, tetapi jawaban terhadap tantangan dari modernisasi dan globalisasi itu sendiri. Maka dari itu, seni pertunjukan tradisional juga harus berkembang tanpa harus meninggalkan akar tradisinya.

Penyajian pertunjukan Wayang Hip-Hop untuk personil sengaja dikonsep hanya terdiri dari 1 dalang, 3 pemusik, 3 penyanyi, dan 1 teknisi yang menangani alat musik dan sound control serta beberapa alat-alat pendukung tambahan lainnya. Sedangkan alat musik menggunakan 1 keyboard, 1 laptop, 1 guitar akustik, 1 siter, dan sejumlah perkusi seperti kendang, terbang, rebana, dan lainnya.

\section{Proses Munculnya Wayang Hip Hop}

Pandangan Parsons tentang tindakan yang diuraikan oleh Hendar Putranto (2005: 55) dalam Budaya dan Integrasi Sosial, Menelusuri Jejak Karya Talcott Parsons, menyebutkan bahwa sebuah model ideal tindakan manusia harus mempunyai unsur: (1) Tujuan $($ ends) $=$ tujuan tindakan; (2) Sarana (means) $=$ hal-hal yang memampukan si pelaku bertindak; (3) Syarat (conditions) = situasi-situasi dan batasan-batasan yang melingkupi tindakan; (4) Norma (norms) = pemahaman atas tujuan dan sarana mana yang sesuai dan bisa diterima; (5) Upaya (effort) = kerja atau upaya yang dikerahkan pelaku untuk menyelesaikan tindakan.

Berdasarkan teori tindakan Parsons, maka dapat dijawab mengapa bentuk sajian Wayang Hip Hop menghancurkan/meleburkan dua budaya besar. Dari hasil data lapangan, data wawancara, studi kasus dan tahap penganalisisan data, bentuk sajian Wayang Hip Hop didasari oleh tujuan dari pelaku seni yang ada di dalamnya untuk menghidupkan kembali keberadaan pertunjukan wayang kulit di Yogyakarta.

Wayang Hip Hop merupakan suatu pergelaran seni yang menggabungkan unsur budaya barat dan budaya timur (budaya Jawa), yaitu antara seni pewayangan dan musik Hip Hop. Wayang Hip Hop pertama kali didirikan oleh Ki Catur Kuncoro, yang sering dipanggil dengan Ki Benyek pada tanggal 10 Juni 2010 di Yogyakarta. Ki Catur Kuncoro lahir dalam keluarga dalang wayang kulit purwa. Beliau lahir tanggal 03 Maret 1975 dan besar di Kadipiro no.267 Rt.07 Ngestiharjo, Kasihan, Bantul. 55182. Sebelum menjadi dalang Wayang 
Hip Hop, Ki Catur adalah seorang dalang wayang kulit purwa. Beliau adalah putra seorang seniman khususnya dalang ternama di Daerah Istimewa Yogyakarta yaitu Ki Supardi. Ki Catur adalah tipe salah seorang dalang yang kritis, inovatif, dan humoris. Sampai saat ini banyak pementasan yang sudah dilakukannya. Selain dikenal sebagai seorang dalang, dia juga terkenal sebagai seorang musisi. Berbagai jenis aliran musik dapat dimainkannya, baik musik tradisional, kontemporer bahkan musik modern juga bisa dimainkannya. Ki Catur mencoba mengembangkan/mengenalkan seni tradisi wayang kulit kepada para pemuda khususnya di Yogyakarta. Dengan cara kreatifnya, Ki Catur memunculkan karya seni Wayang Hip Hop.

Ki Catur dalam hal ini berperan sebagai dalang Wayang Hip Hop. Ki Catur berperan sebagai komunikator sosial dengan melakukan kritik sosial melalui lawakan tokoh punakawan dan menjabarkan harapan dari rakyat, oleh rakyat, dan untuk rakyat melalui syair-syair dengan musik hip hop. Menurut Ki Catur Kuncoro, Wayang Hip Hop hanya merupakan ungkapan dari keresahan rakyat kecil atas ulah elit yang kadang sulit dipahami. Karena hanya merupakan 'gerutu' dari rakyat, Ki Catur mengatakan, pentas Wayang Hip Hop tidak memberikan solusi bagi persoalan sosial yang sedang diangkat. Pentas sekadar ingin mengajak penonton tertawa, menertawakan semua peristiwa yang ternyata hanyalah dagelan hidup (wawancara, 6 November 2014). Sedangkan dipilihnya media wayang, karena tokoh-tokoh dalam wayang sangat mewakili karakter manusia. Kemudian didekonstrusi dengan musik hip hop yang pada awal mulanya merupakan sarana kritik sosial sekaligus musik yang digemari kalangan muda yang notabene menjadi sasaran audiens Wayang Hip Hop. Namun kondisi sosial masyarakat telah berubah maka perlu adanya perubahan untuk menarik minat masyarakat terhadap kesenian tradisi, khususnya wayang. Melalui musik Hip Hop, Ki Catur mendekonstruksi wayang kulit purwa.

Disebut Wayang Hip Hop karena selama pementasan wayang diiringi lagu hip hop, khas anak muda. Walaupun menggunakan musik hip hop, pentas Wayang Hip Hop tetap sarat nuansa tradisi. Syair dalam musik hip hop banyak menggunakan bahasa Jawa yang sarat falsafah Jawa. Kedudukan musik digunakan untuk lebih mendramatisir suasana dengan aransemen yang ilustratif. Musik Hip-hop merupakan salah satu musik yang paling utama dalam pertunjukan tersebut. Dipilihnya musik Hip Hop selain digunakan untuk mendramatisir suasana, juga karena musik Hip Hop saat ini merupakan salah satu jenis musik yang digandrungi oleh anak-anak muda zaman sekarang. Dipilihnya KM7 Hip Hop sebagai bagian satu kesatuan yang membaur dalam kelompok Wayang Hip Hop juga tidak terlepas dari pemikiran dan filosofi dari musik hip hop itu sendiri. Di negara asalnya, musik Hip Hop adalah musik yang mengunakan lirik-lirik nakal dan tajam dalam mengkritik kondisi sosial masyarakat. Musik Hip Hop terasa kurang lengkap tanpa MC. Celah inilah yang dilihat oleh Melle Mel, MC pertama pada dunia Hip Hop. Pada awalnya Melle Mel merasa bingung apa yang akan diucapkannya pada penampilan pertamanya tersebut, namun karena dirinya telah dipenuhi kebosanan dengan peraturan-peraturan dari pemerintah yang mengekang, akhirnya Melle Mel mengeluarkan rasa bencinya pada pemerintah dan pandangannya tentang kehidupan lewat lirik-liriknya. Mulai saat itu musik Hip Hop lebih banyak menceritakan tentang kehidupan disekitar masyarakat kulit hitam dan teriakan-teriakan serta protes suara hati mereka kepada pemerintahan yang berlaku tidak adil (wikipedia.org/wiki/Musik_hip_hop). Lirik-lirik musik Hip Hop cenderung keras dan tegas. Begitu juga dengan pemusik KM7 Hip Hop, mereka menciptakan lagu-lagu Hip Hop yang kritis dan energik dengan menggunakan bahasa Jawa dan bahasa Indonesia. Namun demikian Wayang Hip Hop tetap berusaha mengalunkan lagu-lagu Jawa, tembang kenangan, dan dangdut dengan tujuan membuat suasana pagelaran menjadi lebih hidup dan tidak membosankan tanpa meninggalkan ciri khas musik hip hop yaitu pesan maupun kritikan sosial yang bersifat tegas dan keras.

Bagi komunitas Wayang Hip-Hop khususnya Ki Catur, berkesenian harus selalu berinovasi, jika tidak demikian maka akan ketinggalan dan ditinggal zaman. Maka dari itu Ki Catur menciptakan Wayang Hip Hop sebagai upaya mengenalkan kembali wayang kepada anak muda dan masyarakat urban yang sebagian besar sudah tidak mengenal dan tidak lagi menyukai wayang purwa klasik. Untuk mempertahankan eksistensi Wayang Hip 
Hop diciptakanlah tema-tema yang menarik dan bervariatif setiap pementasan, kreasi wayang yang menarik dengan menampilkan tokoh-tokoh baru dalam pewayangan, menggunakan jejaring sosial facebook, twitter, blog, dan youtube untuk mengenalkan Wayang Hip Hop, menyajikan lagu yang menarik dan terkonsep, melakukan kolaborasi dengan seniman lain, berinteraksi dengan penonton, mengajak penonton berpartisipasi, sikap kompak dan semangat, dan memanfaatkan peran media massa (Olifiadriani, 2013).

\section{Wayang Hip Hop Sebuah Dekonstruksi}

Berdasarkan pemikiran dekonstruktif Derrida (Sutrisno, 2005), bahwa ada pemikiran lain yang bisa menjadi pemikiran alternatif di samping pemikiran yang telah ada, menawarkan konsep baru untuk menggantikan konsep lama, dan penghancuran/pembongkaran gambar/tampilan yang sebelumnya mendominasi, mendukung apa yang tersembunyi, dan yang didominasi; maka Wayang Hip Hop adalah sebuah dekonstruksi. Hal tersebut dibuktikan adanya peleburan pada wayang kulit purwa. Pertama unsur properti boneka wayang mengalami pemodernisasian dari segi busana dan hanya menampilkan tokoh punakawan seperti Semar, Gareng, Petruk, dan Bagong. Ki Catur juga menambahkan tokoh artisartis Ibu Kota maupun artis internasional untuk membaur bersama punakawan. Boneka wayang kayon/gunungan digantikan dengan adanya wayang pohon-pohonan. Kemudian properti kelir tidak nampak lagi dalam sajian Wayang Hip Hop. Pakaian dalang yang mengkombinasikan antara pakain adat Jawa dengan pakaian modern seperti sepatu kets, kaca mata hitam dan sebagainya. Unsur lakon juga tidak mengikuti pakem yang ada dan lebih bersifat gambaran kehidupan masyarakat umum. Hanya menampilkan adegan gara-gara yang lebih bersifat memasyarakat, sesuai dengan esensi dan tujuan Wayang Hip Hop sebagai komunikator sosial dengan melakukan kritik sosial. Catur atau antawecana menggunakan bahasa Jawa yang dipakai sebagai bahasa sehari-hari dicampurkan dengan bahasa Indonesia. Selain itu, unsur gamelan Jawa tidak lagi terdapat dalam sajian pertunjukan Wayang Hip Hop, melainkan musik Hip Hop dengan syair-syair berbahasa campuran bahasa Jawa dan bahasa Indonesia. Musik Hip Hop dalam hal ini mengalami peleburan dalam hal bahasa syair lagu yang bertujuan agar mudah dimengerti dan diterima masyarakat luas.

Pada langkah yang kedua, melibatkan penghancuran/pembongkaran kedua kutub, tetapi pada saat yang sama juga berlangsung perpindahan pada mereka, dan kesemuanya itu kemudian membangun suatu yang baru dan lebih luas. Wayang Hip Hop menghancurkan dua budaya yaitu wayang kulit Purwa dan musik Hip Hop. Konsep kreatifitas Ki Catur Kuncoro dalam memunculkan sesuatu yang baru mampu diterima masyarakat luas khususnya di Yogyakarta. Ki Catur menggabungkan dua kebudayaan tersebut dengan cara mendekonstruksi suatu kebudayaan yang sudah mapan di lingkungan masyarakat tertentu dengan budaya manca untuk mencapai tujuan yang diharapkan. Kedua budaya tersebut adalah wayang kulit purwa yang didekonstruksi dengan musik hip hop.

\section{Penutup}

Penyajian Wayang Hip Hop menunjukkan adanya perubahan kebudayaan di tengah kehidupan sosial masyarakat Yogyakarta yang dinamis. Perubahan tersebut yaitu proses dekonstruksi musik hip hop terhadap wayang kulit purwa yang dilakukan oleh Ki Catur Kuncoro. Fenomenafenomena yang dijumpai membuktikan bahwa budaya tradisi dapat disejajarkan dengan yang modern. Tujuan dari munculnya Wayang Hip Hop tersebut tidak terlepas dari esensi musik hip hop yaitu musik yang menggunakan liriklirik nakal dan tajam dalam mengkritik kondisi sosial masyarakat. Selain hal tersebut dipilihnya musik hip hop dikarenakan musik hip hop banyak digemari kalangan muda khususnya di Yogyakarta. Dengan demikian, dekonstruksi budaya tersebut selain sebagai kritik sosial sekaligus sebagai upaya pengenalan kembali wayang kulit kepada kaum muda khususnya di Yogyakarta yang mulai meninggalkan wayang sebagai budaya tradisi.

\section{Kepustakaan}

Haryanto, S. 1988. Pratiwimbo Adilihung, Sejarah dan Perkembangan Wayang. Jakarta: Djambatan. 
Murtiyoso, Bambang dkk. 2004. Pertumbuhan dan Perkembangan Seni Pertunjukan Wayang. Surakarta: Citra Etnika Surakarta.

Olifiadriani, Vatu. 2013. "Eksistensi Wayang Hip Hop Di Yogyakarta Sebagai Terobosan Baru Mengenalkan Wayang Kepada Generasi Muda" dalam Jurnal E Societas, Vol. 5. Yogyakarta: Universitas Negeri Yogyakarta.

Putranto, Hendar. 2005. Teori-teori Kebudayaan. Yogyakarta: Penerbit Kanisius.

Sukistono, Dewanto. 1988. Pembuatan Wayang Golek Menak Bapak Darso Sumarto di Yogyakarta. Yogyakarta: Laporan Kerja Lapangan SMK 1 Negeri Yogyakarta.

Supanggah, Rahayu. 2009. Bothekan Karawitan II. Surakarta: ISI Press Surakarta.

Supriyono. 2007. "Fungsi Gending Dalam
Pakeliran Jawatimuran”. [makalah]. Surabaya: Taman Budaya Jl. Gentengkeli No. 85 Surabaya,

Sutrisno, Mudji. 2005. Teori-Teori Kebudayaan. Yogyakarta: Kanisius.

Varela, Miguel Escobar. 2014. "Wayang Hip Hop: Java's Oldest Performance Tradition Meets Global Youth Culture" dalam Asian Theatre Journal Volume 31, Number 2.

\section{Narasumber}

Ki Catur Kuncoro/Ki Benyek. Umur 40 tahun. Seorang seniman, dalang Wayang Hip Hop dan dalang Wayang Kulit Purwa. Alamat: Kadipiro No, 267 RT 07 Ngestiharjo, Kasihan Bantul. Yogyakarta. 